Э. Л. Доржиева, Т. К. Кириллова. Стратегия социальной ответственности инновационной деятельности корпорации

УДК 338

DOI 10.18101/2304-4446-2019-2-17-23

\title{
СТРАТЕГИЯ СОЦИАЛЬНОЙ ОТВЕТСТВЕННОСТИ ИННОВАЦИОННОЙ ДЕЯТЕЛЬНОСТИ КОРПОРАЦИИ
}

\author{
(C) Доржиева Эржена Лхамажаповна \\ кандидат экономических наук, \\ Иркутский национальный исследовательский технический университет \\ Россия, 664074, г. Иркутск, ул. Лермонтова, 83 \\ E-mail: delh@rambler.ru
}

(C) Кириллова Татьяна Климентьевна

кандидат экономических наук, доцент, Иркутский государственный университет путей сообщения

Россия, 664074, г. Иркутск, ул. Чернышевского, 5

E-mail:ktasha83@yandex.ru

Инновационная деятельность, с одной стороны, можно рассматривать как ключевой фактор повышения конкурентоспособности корпорации, с другой стороны, разработка и реализация инновационной продукции предполагает высокие риски и повышает сопротивление в обществе. В связи с этим вопросы социальной ответственности инновационной деятельности корпорации, влияющие на различные сферы жизни общества, нуждаются в детальном изучении. В статье рассматривается ее значение для достижения стратегических целей корпорации. Автором определены мотивы социальной ответственности инновационной деятельности корпорации, обоснована необходимость внедрения программ социальной ответственности отечественными корпорациями, представлен обзор методов, позволяющих определить эффективность социальной ответственности корпорации, показана эффективность стратегии социальной ответственности инновационной деятельности корпорации, основанной на сочетании экономических и этических мотивов, а также примеры эффективной деятельности корпораций, практикующих социально ответственное поведение.

Ключевые слова: инновационная деятельность; социальная ответственность; корпорация; стейкхолдеры; стратегия; транспарентность; доверие; этика.

Для цитирования:

Доржиева Э. Л., Кириллова Т. К. Стратегия социальной ответственности инновационной деятельности корпорации // Вестник Бурятского государственного университета. Экономика и менеджмент. 2019. № 2. С. 17-23.

В последние годы отечественные корпорации особое внимание уделяют инновациям и инновационной деятельности. По данным исследований, одним из основных мотивов осуществления инновационной деятельности является создание благоприятного имиджа фирмы [5]. Это является важным конкурентным преимуществом, поскольку потенциальные партнеры, потребители и другие заинтересованные лица принимают решения с учетом роли корпорации в обществе, анализируя политику корпорации в отношении со своими сотрудниками, акционерами и ближайшими соседями.

Инновационная деятельность корпораций управляется экономическими законами, но определяется людьми. Успех на рынке зависит от того, насколько инно- 
вационные расходы сопровождаются сдвигами в корпоративной культуре корпорации, мотивации в принятии стратегических решений. Инновации и инновационная деятельность корпораций поднимают этические вопросы, поскольку имеют серьезные последствия для общества и окружающей среды, создают новые риски. Инновационная деятельность корпораций зависит от социальной приемлемости, и их внедрение требует ответственного этического поведения корпораций.

Известно, «курс на инновацию превращается в стратегию при условии формирования единой системы инновационной деятельности, в которой инновации становятся техническим, экономическим и социальным процессом». Стратегия инновационного развития корпорации предполагает формирование долгосрочных целей инновационной деятельности и выбор наиболее эффективных методов их достижения. Одной из таких долгосрочных целей инновационной деятельности, как уже упоминалось, является благоприятный имидж. В связи с этим, по мнению автора, наиболее эффективным методом достижения данной цели является практика социальной ответственности инновационной деятельности корпорации. Это подразумевает интеграцию в практику ведения бизнеса качественно новых механизмов и форм организации производства и труда, учитывающих интересы работников, потребителей, местного сообщества, и других заинтересованных лиц (стейкхолдеров) [7]. Как правило, такие изменения связаны с корректировкой стратегии корпорации, например, внедрение международных стандартов в системах менеджмента качества и сертификации продукции.

Инновационная деятельность корпорации происходит под воздействием социально-экономических условий, социально направленной политики страны, peгиона, духовной культуры общества. На наш взгляд, следует согласиться с мнением некоторых исследователей, что корпорации, осуществляющие инновационную деятельность, априори должны быть социально ответственными [8].

Социальная ответственность корпораций - ответственность бизнеса за воздействие принимаемых решений и деятельности на общество и окружающую среду через прозрачное и этичное поведение, которое содействует устойчивому экономическому развитию, включая всех заинтересованных сторон. Социальная ответственность отечественных корпораций увеличивается с возрастанием роли корпоративного сектора в экономике. Чем крупнее промышленная корпорация, тем больше влияния она оказывает на окружающую среду, включая сотрудников, потребителей, партнеров, экологическую обстановку, т. е. на деятельность всех стейкхолдеров.

В практике отечественных корпораций программы социальной ответственности бизнеса еще не заняли должного места. Эффективность различных институтов, включая программы социальной ответственности бизнеса, зависит от степени доверия между экономическими субъектами, а значит, и национальных особенностей. Можно выделить несколько важных особенностей: географическое положение России; особенности российского менталитета; социальнополитическую ситуацию в стране [4]. Их необходимо учитывать как в разработке индивидуальных программ социальной ответственности корпораций, так и в разработке политики социальной ответственности российского бизнеса в целом. 
В основе социальной ответственности лежит ориентация корпорации на обеспечение устойчивости ее развития. В связи с этим социальная ответственность инновационной деятельности корпорации приобретает стратегический характер. Это предполагает соблюдение экономических, моральных и социальных обязательств на всех этапах инновационного процесса. Этический аспект инноваций заключается в ответственном поведении новатора и соблюдении данных обязательств.

Формирование стратегии социальной ответственности инновационной деятельности происходит под воздействием социально-экономических факторов, духовной культуры общества, этических норм морали, нравственных ценностей с целью устойчивого экономического развития [5]. Стратегия социальной ответственности инновационной деятельности корпорации формируется с учетом интересов всех стейкхолдеров. В ее основе лежит модель социально ответственного поведения корпорации в долгосрочной перспективе. Стратегия социальной ответственности инновационной деятельности корпорации представляет собой комплекс мероприятий: организация системного взаимодействия со стейкхолдерами в целях соблюдения их интересов и минимизации инновационных рисков; формирование инновационной политики, определяющей цели, задачи и систему мер по ключевым направлениям инновационной деятельности корпорации; внедрение систем менеджмента, направленных на повышение качества управления инновациями и реализацию принципов устойчивого развития; повышение транспарентности и информационной открытости инновационной деятельности корпорации; определение ключевых направлений для оценки эффективности реализации стратегии социальной ответственности инновационной деятельности.

Стратегической целью социальной ответственности инновационной деятельности корпораций должно быть повышение благосостояния и общее повышение качества жизни. Достижение этих целей возможно благодаря стимулированию инновационной деятельности корпораций посредством привлечения лучших сотрудников, необходимо инвестировать в повышение квалификации сотрудников, создавать благоприятную обстановку для новаторства. Постепенно социально ответственное поведение становится важнейшей составляющей инновационной деятельности корпорации. Сравнительно недавнее исследование Гарвардского университета показало, что корпорации, учитывающие интересы всех стейкхолдеров социальной ответственности, имеют показатели роста в четыре раза больше и показатели роста занятости в восемь раз больше в сравнении с фирмами, которые сфокусированы только на интересах акционеров [1].

Инновационная деятельность корпорации, сопряженная с ориентацией на защиту окружающей среды и улучшение условий труда, позволит значительно сокращать расходы корпорации за счет снижения производственных отходов и неэффективности переработки или за счет повышения производительности труда. Например, многие инициативы, направленные на сокращение выбросов газов, влияющих на глобальное изменение климата, также увеличивают энергоэффективность производства путем уменьшения расходов на коммунальные услуги. Многие инициативы по вторичной переработке также сократили расходы по вывозу и уничтожению отходов производства и генерировали прибыль от продажи материалов вторичной переработки. В области кадровых ресурсов результатом 
программ пожизненного найма стало снижение пропусков работы и повышение показателя удержания сотрудников, что часто приводит к финансовой экономии корпорации за счет роста производительности и снижения расходов на наем и подготовку новых сотрудников. Таким образом, к экономическим преимуществам корпоративной социальной ответственности относят минимизацию не только трансакционных, но и операционных издержек [2].

Крупные отечественные промышленные корпорации, осуществляющие инновационную деятельность, переходят на международные стандарты корпоративного управления, внедряя в том числе и программы социальной ответственности. Как утверждают специалисты, наибольшую активность во внедрении стандартов социальной ответственности проявляют корпорации, которым нужен выход на мировой рынок. Лидеры российского бизнеса на протяжении нескольких лет развивают социальные, экологические и партнерские программы в регионах присутствия своих предприятий, причем при реализации этих программ используется все более системный подход. Их примеру следуют и другие компании. Социальная ответственность бизнеса постепенно получает более широкое распространение и в регионах России. В 2016 г. в конкурсе высокой социальной ответственности приняли участие более 800 организаций из 70 регионов России ${ }^{1}$.

Вопросы эффективности реализации программ корпоративной социальной ответственности промышленных корпораций рассмотрим на основе теоретических и методических положений [4]. Подробный анализ современных методик для оценки эффективности деятельности корпораций в сфере социальной ответственности бизнеса содержится в работах Е. В. Корчагина и О. А. Лещенко ${ }^{2}$ [6]. Экономическую эффективность социальной ответственности корпорации можно оценить на основе методики SROI (Social Return on Investment). Данная методика учитывает «социальное и экологическое воздействие - результаты инвестиций, описывая происходящие изменения, основываясь на восприятии и оценке отдельных заинтересованных сторон, по возможности представляя количественные результаты показателей. Среди методик оценки социальной эффективности, основывающихся преимущественно на качественном анализе данных, выделяют SIA (Social Impact Assessment), SRA (Social Return Assessment), SCBA (Social CostsBenefit Analysis), SVA (Stakeholder Value Added), а также международные принципы оценки социальных последствий и результатов (IAIA, International Assosiation for Impact Assessment). Социальный эффект социальной ответственности бизнеса регулярно оценивают Коалиция экологически ответственных экономик (CERES), Институт социальной и этической ответственности (ISEA). Ра3работаны стандарты социальной отчетности (AA1000, GRI, ISO, SA8000)»³.

Во многих исследованиях значимыми условиями сравнения промышленных корпораций с точки зрения эффективности реализации программ социальной ответственности бизнеса являются срок жизни, размер корпорации, а также стоимость корпорации. Также оценка эффективности социальной ответственности

${ }^{1}$ Институт комплексных стратегических исследований [Электронный ресурc]. URL: http://www.icss.ac.ru

2 Практическое руководство по организации взаимодействия со стейкхолдерами [Электронный ресурc]. URL: www.StakeholderResearch.com

${ }^{3}$ Там же. 
Э. Л. Доржиева, Т. К. Кириллова. Стратегия социальной ответственности инновационной деятельности корпорации

бизнеса может основываться на анализе данных известных рейтингов и индексов: DEA (Data Envelopment Analysis) и KLD (Kinder, Lydenberg, and Domini) ${ }^{1}$. DEA предполагает сравнение определенных показателей с лучшими показателями подобных корпораций. На основе данного показателя осуществляется оценка финансовых показателей. Результаты данных расчетов характеризуют связь с показателями социальной ответственности, что отражает зависимость между высокими показателями социальной ответственности корпораций и экономической эффективностью. Результаты исследований западных ученых М. Стьюбса и Л. Сана выявили положительную связь этих показателей${ }^{2}$. Индекс KLD является одним из часто применяемых показателей эффективности социальной ответственности, на его основе ежегодно анализируются данные корпораций по различным направлениям: отношения с работниками, права работников, экологическая среда и другие направления. В результате анализа определяется индекс социальной ответственности компании. Однако следует отметить, что многочисленные исследования влияния социальной ответственности бизнеса на эффективность экономического развития промышленных корпораций показывают различные результаты.

Эффективность оценивания социальной ответственности бизнеса состоит из 4 основных этапов (рис. 1).

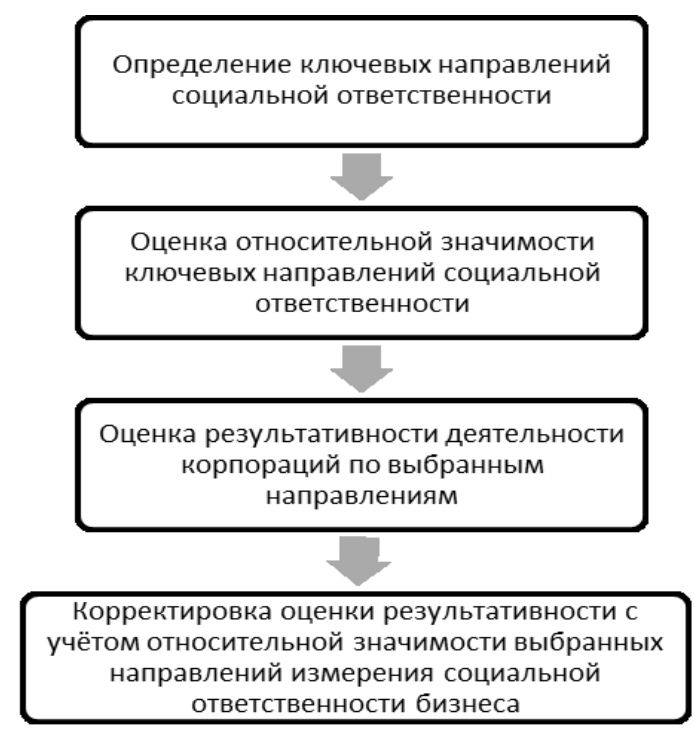

Рис. 1. Этапы оценки социальной ответственности бизнеса

Индекс экономического эффекта позволяет оценить суммарный эффект воздействия промышленной корпорации на местное сообщество. Данный подход

1 Практическое руководство по организации взаимодействия со стейкхолдерами [Электронный ресурc]. URL: www.StakeholderResearch.com

${ }^{2}$ Stuebs M., Sun L. Social responsibility and firm efficiency in the business services industry. 2010 [Электронный pecypc]. URL: http://www.csringreece.gr/files/research/CSR1290004161.pdf 
позволяет оценить различные направления социальной ответственности бизнеса, не зависит от характеристик корпорации, отражает ценности выбранных для анализа групп стейкхолдеров ${ }^{1}$.

Следует отметить, что универсальных методологических подходов к измерению эффективности социальной ответственности нет, поскольку значимость ключевых направлений социальной ответственности бизнеса может меняться в зависимости от разных факторов. Социальная ответственность инновационной деятельности корпорации может быть эффективной, будучи добровольной. Корпорация определяет объемы и направление своей социальной деятельности, самостоятельно определяет приоритеты, баланс между своими интересами и интересами стейкхолдеров.

По нашему мнению, социальная ответственность корпорации, соблюдение этических норм - критерий, характеризующий не только успешное развитие отдельной корпорации, но и уровень развития общества в целом. Корпорация, отказываясь от кратковременной выгоды, при этом не нарушая этических правил, являясь социально ответственной, выбирает большую выгоду в долгосрочной перспективе, таким образом, действует стратегически рационально, обеспечивает устойчивое экономическое развитие. Стратегия социальной ответственности инновационной деятельности эффективна, если этические нормы общеприняты в данном обществе и если корпорации безразлично, какие стратегии выбирают другие фирмы. Следование принципам социальной ответственности инновационной деятельности способствует более эффективному достижению корпорациями их стратегических целей [3].

Отечественные корпорации, понимающие значение социальной ответственности инновационной деятельности, рассматривают ее как конкурентное преимущество. Сотрудничество на основе доверия и честности, с учетом и пониманием интересов всех стейкхолдеров позволяет достигнуть лучших результатов инновационной деятельности, поскольку создается фундамент для синергии, возникновения инноваций, ценность которых возрастает. Социально ответственное поведение в сфере инновационной деятельности помогает корпорациям упрочить успешную стратегию развития на длительную перспективу, это инвестиция в устойчивое экономическое развитие.

\section{Литература}

1. Бикеева М. В., Иванова И. А., Влияние социальных инвестиций на инвестиционную привлекательность компании // Менеджмент в России и за рубежом. 2015. № 6. С. 12-18.

2. Доржиева Э. Л. Экономика и секулярная этика: аспекты взаимодействия // Философия хозяйства. 2015. № 2. С. 50-54.

3. Корпоративная социальная ответственность / Т. В. Дорожкина [и др.]. Калуга, 2015. $178 \mathrm{c}$.

4. Зарецкий А. Д. Корпоративная ответственность: мировая и отечественная практика. Краснодар: КСЭИ, 2012. 231 с.

5. Косикова Ю. А., Пирогова Н. А. Корпоративная социальная ответственность традиции компании «Нестле Россия» // Молодой ученый. 2016. № 26. С. 326.

1 Практическое руководство по организации взаимодействия со стейкхолдерами [Электронный ресурc]. URL: www.StakeholderResearch.com 
Э. Л. Доржсиева, Т. К. Кириллова. Стратегия социальной ответственности инновационной деятельности корпорации

6. Лещенко О. А., Корчагина Е. В. Современные методики оценки эффективности деятельности компаний в области КСО // Менеджмент в России и за рубежом. 2014. № 1. C. $11-18$.

7. Романова О. А., Ткаченко И. Н. Социальная ответственность корпораций: опыт территориального исследования // Экономическая наука современной России. 2011. № 2. C. $23-36$.

8. Шилина М. Г. Responsible Innovation, ответственные инновации как фактор социальной ответственности корпорации: формируя концептуальную рамку исследования [Электронный ресурс] // Медиаскоп. 2017. Вып. 2. URL: http://www.mediascope.ru (дата обращения: 10.02.2019).

\section{SOCIAL RESPONSIBILITY STRATEGY \\ OF CORPORATE INNOVATION ACTIVITY}

Erzhena L. Dorzhieva

Cand. Sci. (Econ.),

Irkutsk National Research Technical University

83 Lermontova St., Irkutsk 664074, Russia

E-mail: delh@rambler.ru

Tatyana K. Kirillova

Cand. Sci. (Ekon.),

Irkutsk State Transport University

5 Chernyshevskogo, Irkutsk 664074, Russia

On the one hand, innovative activity is considered as a key factor for improving the competitiveness of a corporation, on the other hand, the development and sale of innovative products implies high risks and increases resistance in society. In this regard, the problems of social responsibility of corporate innovation activity, affecting various spheres of society, should be studied in detail. The article discusses the significance of social responsibility of innovation activity for achieving the strategic goals of the corporation. We have identified the motives for social responsibility of the corporate innovation activities, substantiated the need to introduce social responsibility programs by domestic corporations, made an overview of the methods for determining the effectiveness of corporate social responsibility, presented the effectiveness of social responsibility strategy of corporate innovation activity based on a combination of economic and ethical motives, as well as the examples of the effective performance of corporations that practice socially responsible behavior.

Keywords: innovation activity; social responsibility; corporation; stakeholders; strategy; transparency; trust; ethics. 